\title{
Letters
}

\section{The Effect of 4-hydroxybenzaldehyde on the $\gamma$-aminobutyric Acid Type A Receptor}

\author{
Jingli Z HANG $^{2}$, Habsah MoHAMAD ${ }^{5}$, Jia Hui WonG ${ }^{2}$, Muhammad \\ BILAL ${ }^{2}$, Abdul Hadi Bin ISMAIL ${ }^{5}$, Amelia Jane LloYD ${ }^{1,2}$, Abdul Aziz \\ Mohamed Yusoff ${ }^{1,2}$, Hasnah Osman ${ }^{4}$, Kok Tong Wong ${ }^{4}$, Zamzuri \\ IDRIS ${ }^{1,2,3}$, Jafri Malin ABDULLAH ${ }^{1,2,3}$
}

Submitted: 13 Jan 2017 Accepted: 26 Jan 2017 Online: 14 Apr 2017
1 Center for Neuroscience Services and Research, Universiti Sains Malaysia, Jalan Hospital Universiti Sains Malaysia, 16150 Kubang Kerian, Kelantan, Malaysia

2 Department of Neurosciences, School of Medical Sciences, Universiti Sains Malaysia, Jalan Hospital Universiti Sains Malaysia, 16150 Kubang Kerian, Kelantan, Malaysia

3 Jabatan Neurosains, Hospital Universiti Sains Malaysia, Jalan Hospital Universiti Sains Malaysia, 16150 Kubang Kerian, Kelantan, Malaysia

4 School of Chemical Sciences, Universiti Sains Malaysia, 11800 USM, Pulau Pinang, Malaysia

$5 \quad$ Institut Bioteknologi Marin, Universiti Malaysia Terengganu, 21030 Kuala Terengganu, Terengganu, Malaysia

To cite this article: Zhang J, Mohamad H, Wong JH, Bilal M, Ismail AH, Lloyd AJ, Mohamed Yusoff AZ, Osman H, Wong KT, Idris Z, Abdullah JM. The effect of 4-hydroxybenzaldehyde on the $\gamma$-aminobutyric acid type A receptor. Malays J Med Sci. 2017;24(2):94-99. https://doi.org/10.21315/mjms2017.24.2.12

To link to this article: https://doi.org/10.21315/mjms2017.24.2.12

Abstract

The $\alpha_{1} \beta_{2} \gamma_{2}$ subtype of $G_{A B A_{A}}$ receptors is the most commonly found $G A B A_{A}$ receptor subtype in the mammalian cortex and hippocampus. It is expressed heterologously in the Xenopus laevis oocyte as a $\alpha_{1} \beta_{2} \gamma_{2} S / L$ subtype for application as an in vitro model for the screening of compounds that modulate receptor activities. In fact, 4-hydroxybenzaldehyde (4-HB) has been identified as one of the major components in Dendrocalamus asper bamboo shoots in our previous study, and the current study showed that at $101.7 \mu \mathrm{M}, 4-\mathrm{HB}$ significantly reduced the GABA-induced chloride current of $\mathrm{GABA}_{\mathrm{A}}$ receptors expressed on Xenopus oocytes, indicating a possible GABAergic antagonistic effect at high concentrations.

Keywords: $\alpha_{1} \beta_{2} \gamma_{2} G A B A_{A}$ receptor, electrophysiology, Xenopus oocytes, bamboo shoot, GABAergic agents

\section{Introduction}

$\mathrm{GABA}_{\mathrm{A}}$ receptors, major contributors of neuronal inhibitory responses, are activated by an endogenous neurotransmitter GABA that leads to a rapid influx of chloride ions while the binding of GABA onto metabotropic $\mathrm{GABA}_{\mathrm{B}}$ receptors leads to slow neurotransmission of potassium ion flux (1). The isoform of $\mathrm{GABA}_{\mathrm{A}}$ receptors commonly consists of five subunits two $\alpha 1$, two $\beta_{2}$ and one $\gamma_{2}-$ and it is the most abundantly expressed combinations in the brain $(2,3)$. Due to the rapid inhibitory responses of $\mathrm{GABA}_{\mathrm{A}}$ receptors, it is widely expressed as $\alpha_{1} \beta_{2} \gamma_{2} S / L$ on the membrane of Xenopus laevis oocytes and used as an in vitro model coupled with the two-electrode voltage clamp method to screen for potential modulatory compounds that could enhance or reduce chloride current through $\mathrm{GABA}_{\mathrm{A}}$ receptors $(4,5)$. In traditional Chinese medicine (TCM), bamboo is used as a component to reduce the energy of 'fire' and 
used in TCM as treatment for hypertension, cardiovascular disease and arteriosclerosis. Its extract contains phytochemicals, such as flavanoids, saponin and triterpenoids, that have been shown to possess an antiepileptic effect, suggesting its potential for the treatment of epilepsy (6). As the GABAergic function plays an important role in the mechanism and treatment of epilepsy (7), this study investigated the effect of 4-hydroxybenzaldehyde (4-HB) identified in Dendrocalamus asper bamboo shoots on $\mathrm{GABA}_{\mathrm{A}}$ receptors of the $\alpha_{1} \beta_{2} \gamma_{2} S$ subtype.

\section{Materials and Methods}

\section{Expression in Xenopus oocytes}

The procedures to prepare $\mathrm{DH}_{5}$ a competent cells were carried out and the cDNA of subunits $\alpha_{1}, \beta_{2}$ and $\gamma_{2} \mathrm{~S}$ were cloned in the pCMV vector using the competent $\mathrm{DH}_{5} \alpha$ bacteria. Linearisation and in vitro transcription were performed and the cRNA of each subunit was then isolated and purified. The final $12 \mu \mathrm{L}$ $\left(\alpha_{1}: \beta_{2}: \gamma_{2} S\right.$ by $\left.1: 1: 10\right)$ aliquot (with the final concentration of $20-200 \mathrm{ng} / \mu \mathrm{L}$ for each cRNA) were stored at $-80{ }^{\circ} \mathrm{C}(8,9)$. Surgery was performed on an anesthetised Xenopus laevis female frog to obtain oocyte lobes. The oocyte lobes were cut into small pieces and placed in a modified OR-2 solution (in $\mathrm{mM}: 82 \mathrm{NaCl}$, 5 HEPES, $1 \mathrm{MgCl}_{2}$, $2 \mathrm{KCl}, 1 \mathrm{Na}_{2} \mathrm{HPO}_{4}, 1$ ascorbic acid, $\mathrm{pH}$ 7.5), treated with type II collagenase $(1 \mathrm{mg} / \mathrm{mL})$ for 1 hour under $16{ }^{\circ} \mathrm{C}$ on a rotator. The oocytes were kept in a modified ND96 solution (in mM: $96 \mathrm{NaCl}, 2 \mathrm{KCl}, 1 \mathrm{MgCl}_{2}$, $1.8 \mathrm{CaCl}_{2}, 5$ HEPES, 1 Na-Pyruvate, $0.01 \mathrm{mg} / \mathrm{mL}$ Gentamycin, $\mathrm{pH}$ 7.5) in the incubator at $18{ }^{\circ} \mathrm{C}$ overnight. Oocytes of stage V-VI were selected for the cRNA injection. Each oocyte was injected with $15 \mathrm{~nL}-50 \mathrm{~nL}$ of cRNA and stored in the modified ND96 solution in the incubator at $18{ }^{\circ} \mathrm{C}$ for 48 hours for up to 5 days $(8,9)$.

\section{Drugs}

A total of $44 \mathrm{~kg}$ of Dendrocalamus asper bamboo shoots were harvested from Post Brooke village in Gua Musang, Kelantan and identified by Assistant Botanist, Muhammad bin Deraman from the South Kelantan Development Authority (KESEDAR), with the voucher specimen labeled DAPB52014 and kept in the Department of Neurosciences, School of Medical Sciences, Universiti Sains Malaysia. The bamboo shoots were chopped into $1 \mathrm{~cm}^{3}-2 \mathrm{~cm}^{3}$ pieces and were then lyophilised and ground to yield $6 \mathrm{~kg}$ dried powder of bamboo shoots. One $\mathrm{kg}$ of dried bamboo shoot powder was extracted three times using $800 \mathrm{~mL}$ of dichloromethane for each extraction. The filtered extracts were dried using a rotary evaporator (Buchi, Germany) under reduced pressure, below $40{ }^{\circ} \mathrm{C}$ to yield $31.5 \mathrm{~g}$ of dichloromethane extract. Next, $30 \mathrm{~g}$ of dichloromethane extract were subjected to purification using column chromatography $(4 \mathrm{~cm}$ $\times 30 \mathrm{~cm}, \mathrm{dxh}$ ) packed with silica gel (Merck 1.09385.1000) and eluted with chloroform, and then gradiently increased using ethyl acetate and methanol. The fractions were monitored using thin layer chromatography (Merck 1.05735 silica gel 60 F254). The fractions containing the same spot were combined. Fraction K (2.5 g) containing spot with $\mathrm{Rf}$ value 0.4 (chloroform/ ethyl acetate, 9:1 v/v) were then subjected to repeated column chromatography $(1 \mathrm{~cm} \times 25 \mathrm{~cm}$, dxh) using silica gel (Merck 1.09385.1000) and eluted with hexane/acetone, 7:3 v/v. 200 $\mathrm{mg}$ of 4-hydroxybenzaldehyde (4-HB) were purified after re-crystalisation of fraction $\mathrm{K}_{5}$ from hexane/methanol, with a near $98 \%$ purity (Figure 1). $5 \mathrm{mg}$ of 4 - $\mathrm{HB}$ were dissolved in $0.5 \mathrm{~mL}$ of chloroform. $24.84 \mu \mathrm{L}$ of the stock solution above were dissolved into $20 \mathrm{~mL}$ ND96 with $5 \mu \mathrm{M}$ GABA inside for the bath solution in drug groups in two electrode voltage clamp tests.

\section{Animal ethics}

This study was approved by the Animal Ethics Committee Universiti Sains Malaysia on the research project titled 'The Anti-Epilepsy Effects of DA1, DA2 and Fraction 57 et al. from Petung Bamboo (Dendrocalamus asper) Shoots on GABA (A) Receptor, GluA1 Receptor and Kv1.4 Channel' for 40 female Xenopus laevis [No. of Animal Ethics Approval: USM/Animal Ethics Approval/ 2014/ (90) (578)] with a duration of study from November 2014 to November 2017.

\section{Oocyte electrophysiology - two-electrode voltage clamp (TEVC)}

The enhancement effect of the compounds was shown through the TEVC $\mathrm{GABA}_{\mathrm{A}}$ current recording at a holding potential of $-70 \mathrm{mV}$. TURBO TEC-03X amplifier (NPI Electronic GmbH, Tamm, Germany), Digidata 1440A (Molecular Devices, LLC, Sunnyvale, CA, USA) and pClamp 10.3 software (Molecular Devices, LLC, Sunnyvale, CA, USA) were used for data recording. The data were filtered at $100 \mathrm{~Hz}$ and sampled at $500 \mathrm{~Hz}$. Glass pipettes were pulled with vertical puller Narishige PC-10 (Japan) and filled with $3 \mathrm{M} \mathrm{KCl}$, giving a resistance of 


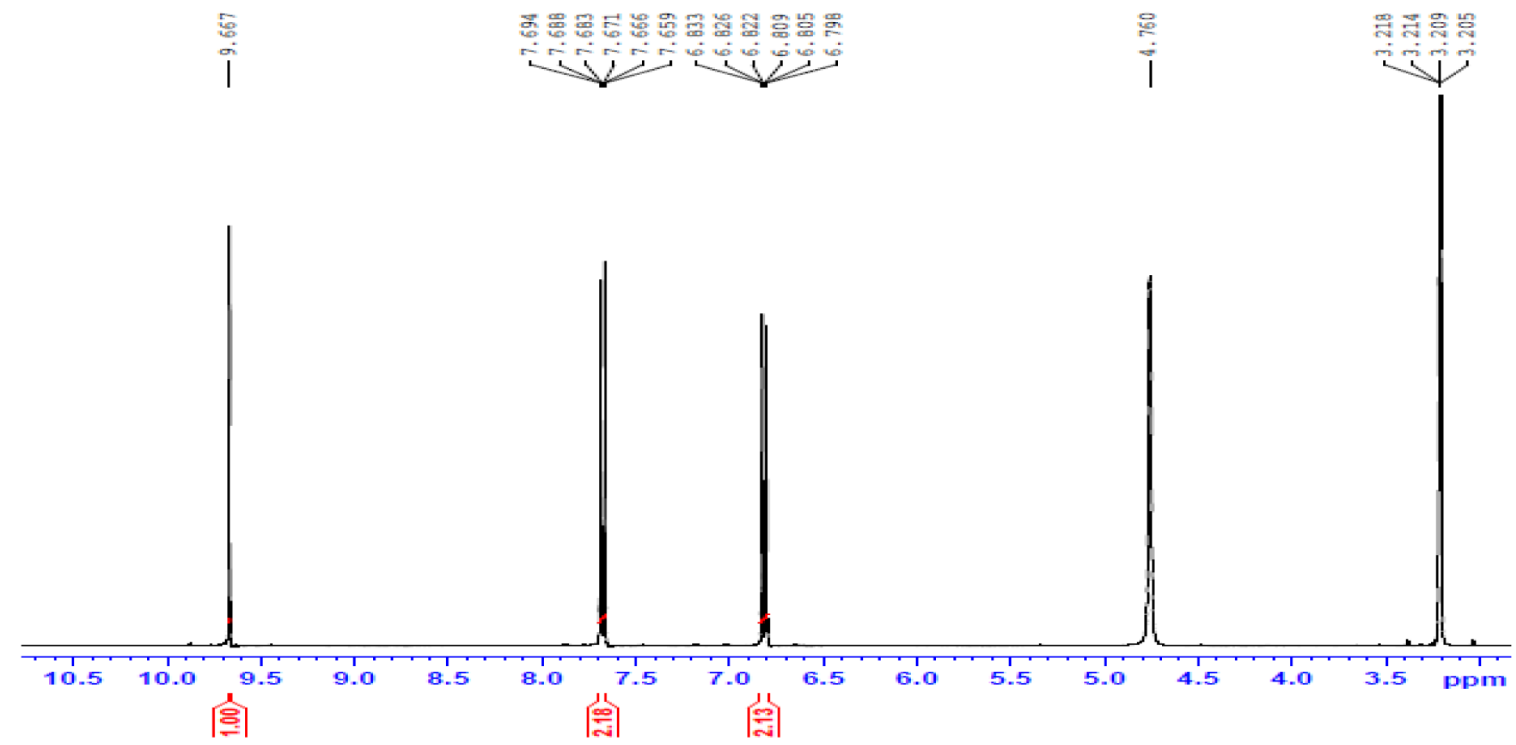

Figure 1. $1 \mathrm{H}-\mathrm{NMR}$ spectrum of p-hydroxybenzaldehyde in Deuterated-methanol (MeOD). Based on the NMR data, there is no impurity peak in the spectrum with purity of 4-HB near to $98 \%$.

0.6 $\mathrm{M} \Omega-1.5 \mathrm{M} \Omega$ of the electrode. ND96 (in $\mathrm{mM}$ : $96 \mathrm{NaCl}, 2 \mathrm{KCl}, 1 \mathrm{MgCl} 2,1.8 \mathrm{CaCl}_{2}, 5$ HEPES, $\mathrm{pH}$ 7.5) was used as a working physiological solution. The $\mathrm{GABA}_{\mathrm{A}}$ response of the control group (in ND96: $\mathrm{EC}_{3}[5 \mu \mathrm{M}] \mathrm{GABA}+$ vehicle chloroform) was compared with the drug groups (in ND96: $\mathrm{EC}_{3} \mathrm{GABA}+4-\mathrm{HB}$ ). By means of an automated fast perfusion system flowing at the rate of $5 \mathrm{~mL} / \mathrm{min}$, the oocytes were exposed to a 4-HB in addition to GABA for 20 seconds with a simultaneous $-5 \mathrm{mV}$ voltage step and followed by a wash-out period of 5 minutes-10 minutes to ensure recovery from desensitisation. The GABA concentration of $\mathrm{EC}_{3}$ (3\% of the maximal current amplitudes) was applied to measure the enhancement effects of the chloride currents by 4-HB (10). Dose-response curves were generated and SigmaPlot software was applied to fit the data by nonlinear regression analysis. The data were fitted into the Hill equation:

$$
I=1+\frac{I_{\max }}{1+\left(\frac{\mathrm{EC}_{50}}{[\mathrm{CPD}]}\right)^{n_{H}}}
$$

$I$ is the current amplitude at a given concentration of agonist [CPD]. $I_{\max }$ is the maximum current response, $\mathbf{E C}_{50}$ is the concentration of the compound which elicits a half-maximal activation, and $n_{H}$ is the Hill coefficient. Normalised current amplitude was reported as mean \pm SEM for at least 6 oocytes and $\geq 2$ batches of oocytes.

\section{Results}

\section{Effect of 4-HB on a GABA-induced current}

A dose-response of GABA (in $\mu \mathrm{M}$ : 0.01, 0.1, $1,5,10,100$, and 1,000 in $20 \mathrm{~mL}$ ND96) was tested on empty oocytes $(n=12)$ and $\mathrm{GABA}_{\mathrm{A}}$ receptor cRNA-injected oocytes $(n=13)$ with a concurrent $-5 \mathrm{mV}$ voltage step (Figure 2). In empty oocytes, the means of normalised current amplitudes for seven concentrations of GABA were 1.0139, 0.9998, 0.9883, 0.9751, 0.9808, 0.9937 and 0.9669 , showing no tendency to increase in the current amplitude as we increased the GABA concentration. In cRNA-injected oocytes, the means of normalised current amplitudes were $0.9491,0.8757,0.9871,1.032$, $1.0255,1.0191$ and 1.077. A tendency to increase in the current amplitude with increasing GABA concentration was observed, indicating a $\mathrm{GABA}_{\mathrm{sf}}$ response in $\mathrm{GABA}_{\mathrm{A}} \mathrm{cRNA}$-injected oocytes, a response not observed in empty oocytes. This demonstrated that there are few native $\mathrm{GABA}_{\mathrm{A}}$ receptors in Xenopus laevis oocytes without the injection of $\mathrm{GABA}_{\mathrm{A}} \mathrm{cRNA}$ and the GABA-induced current was not only due to $-5 \mathrm{mV}$ steps but was also a response of $\mathrm{GABA}_{\mathrm{A}}$ receptors expressed on the oocyte membrane. Based on the mean values of the cRNA-injected oocytes and empty oocytes, a fit of the equation was made. The peak amplitude was partly voltage commanddependent and partly a GABA-induced response; hence, the dose-response curve was different from that which was automatic ligand-induced. 
As the values of the empty oocytes did not suit a reasonable fit, its fit equation was not shown in this paper. For the fit of the $\mathrm{GABA}_{\mathrm{A}} \mathrm{cRNA}$ injected oocytes, the EC5O is $1.521 \mathrm{mM}$, the $\mathrm{nH}$ is 0.6081 and the absolute value of the $I_{\max }$ is 0.1743 (normalised value). The fit equation for cRNA injected group is: $I$ (normalised value) $=$ $1+0.1743 /\left(1+(0.001521 \mathrm{M} /[\mathrm{Comp}])^{0.6081}\right)$. With the input of $5 \mu \mathrm{M}$ GABA into the equation, it was shown that the current amplitude by $5 \mu \mathrm{M}$ GABA was approximately $\mathrm{EC}_{3}$ of the GABA response. The main component of the peak amplitude was the voltage command response in nature. The quickly increased curve phase of the distribution of the peak amplitude did not appear and therefore the EC50 was $1.521 \mathrm{mM}$ after the Hill equation fit. Based on this protocol, $100 \mu \mathrm{M}$ of 4-HB was applied to the perfusion system (ND96 with $5 \mu \mathrm{M}$ GABA) concurrently with a $-5 \mathrm{mV}$ voltage step, and this reduced the GABA-induced chloride current to $0.984 \pm 0.006$ (mean and SEM) as compared with the vehicle control group (Figure 3).

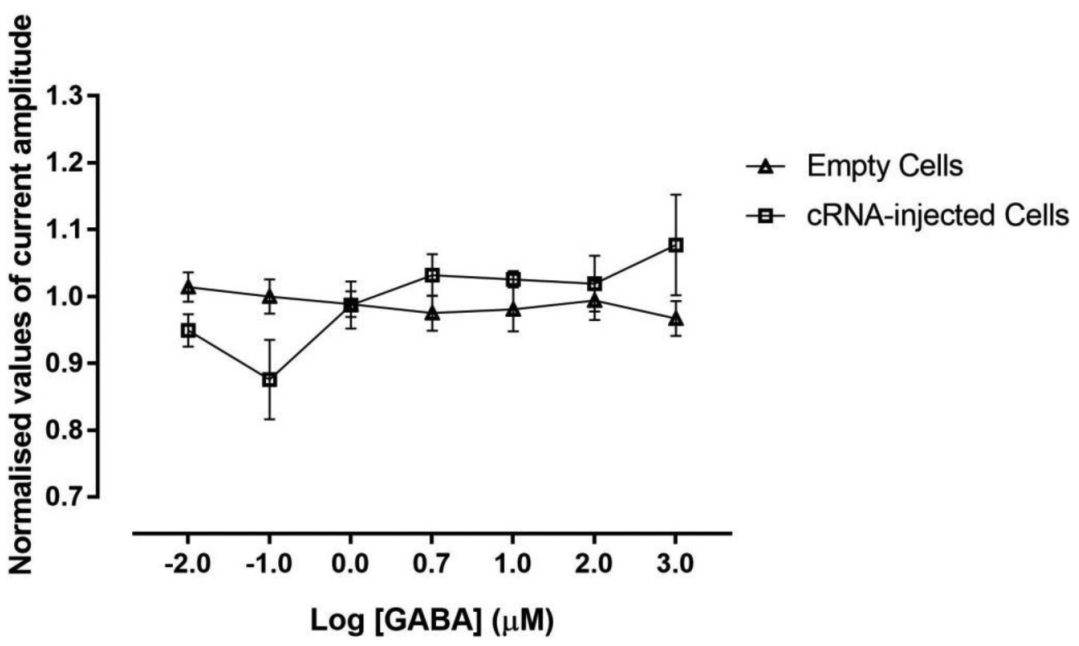

Figure 2. Dose-response of GABA-induced chloride current on empty oocytes and cRNA-injected oocytes. The series of GABA concentrations ranging from 0.01 to $1000 \mu \mathrm{M}$ was tested with a concurrent $-5 \mathrm{mV}$ voltage step for 20 milliseconds during the acute application of GABA in ND96. There was a tendency of an increase in the current amplitude of the GABA-induced current in cRNA-injected cells with increasing GABA concentration, a tendency which was not observed in empty cells.
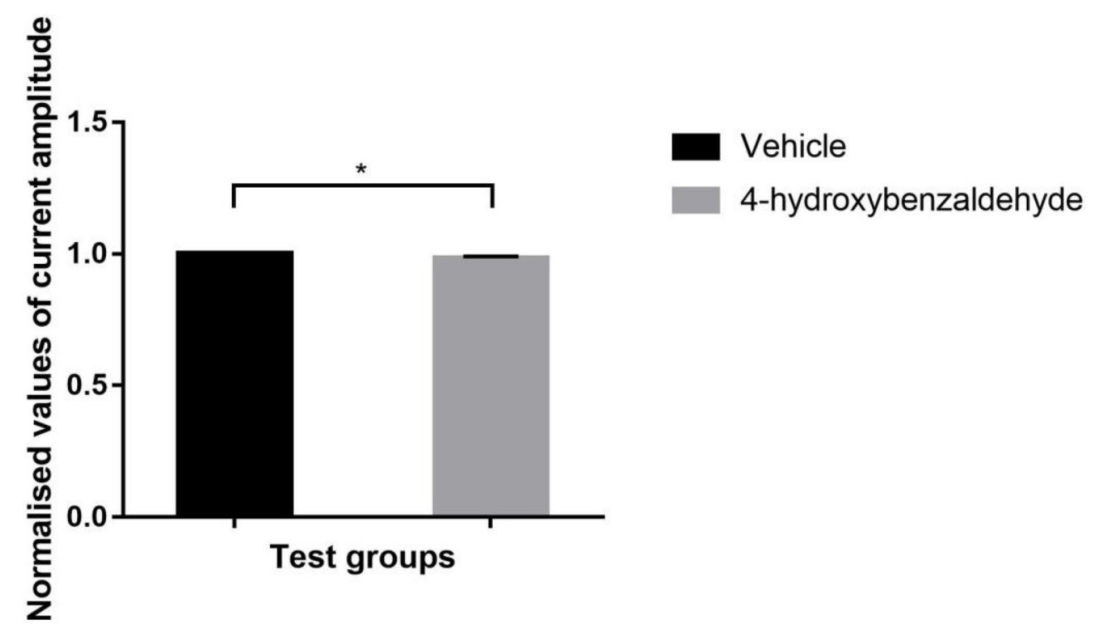

Figure 3. Effect of a 101.7 $\mu \mathrm{M} 4$ 4-HB on GABA-induced chloride current. 4-HB was applied onto recording oocytes expressed with the $\mathrm{GABA}_{\mathrm{A}} \alpha_{1} \beta_{2} \gamma_{2} \mathrm{~S}$ subtype through an automated fast perfusion system and reduced the GABA-induced chloride current $(0.984 \pm 0.006)$ as compared with the vehicle group (Student's $t$-test, $P=0.019, n=8$ ). 


\section{Discussion}

Pharmacological evidence suggested interactions between TCM and $\mathrm{GABA}_{\mathrm{A}}$ receptors; for example, studies on Gastrodia elata demonstrated the potential anticonvulsant activities of this plant with $4-\mathrm{HB}$, one of the major phytochemicals that displayed a positive modulatory effect on GABAergic responses $(11,12)$. It was proposed that the carbonyl and hydroxyl groups enable 4-HB to exert its inhibitory effect on GABA-transaminase through competitive binding, with no indication of reversibility $(13,14)$. At low concentrations, 4-HB was demonstrated to increase chloride influx as well as the expression of $\alpha$ and $\beta$ subunits (15). 4-HB reduced the onset of sleep and the counts of the sleep-wake cycle; it also increased total sleep time and non-rapid eye movement in rodent models, attributable to an enhanced GABAergic function (15). However, our study on $\mathrm{GABA}_{\mathrm{A}}$ receptors expressed on Xenopus oocytes demonstrated a reduction of GABAergic function when $101.7 \mu \mathrm{M}$ of $4-\mathrm{HB}$ was applied acutely onto the cells, as it lowered the GABA-induced chloride currents. This indicated a potential antagonistic effect of 4-HB at high concentrations and more in-depth studies are warranted to identify the dose-response effect of $4-\mathrm{HB}$ as well as its binding mechanism and reversibility on a $\mathrm{GABA}_{\mathrm{A}} \alpha_{1} \beta_{2} \gamma_{2} \mathrm{~S}$ receptor subtype.

\section{Conclusion}

This study demonstrated that acute application of $101.7 \mu \mathrm{M}$ of 4-hydroxybenazaldehyde led to a reduction of a GABA-induced chloride current tested on a $\mathrm{GABA}_{\mathrm{A}}$ receptor of a $\alpha_{1} \beta_{2} \gamma_{2} \mathrm{~S}$ subtype expressed on Xenopus oocytes, suggesting an inhibitory effect of GABAergic responses at a high 4-HB concentration. The findings provided leads for future studies to verify the dose-response effect of 4-HB on a GABA-induced chloride current.

\section{Acknowledgement}

We would like to thank Wan Burhanuddin bin Wan Abidin, Dip Arch (ITM '75), BFA, B.Arch (RISD '79), S. M. Arch. S (MIT '81) (deceased) from the School of Housing, Building and Planning, Universiti Sains Malaysia who initiated the Bamboo Research Cluster, Universiti Sains Malaysia in 2009 and the research into its biocompounds and its effects in epilepsy and other neurological diseases. Associate Professor Dr. Kamarul Imran Musa from the Department of Community Medicine, School of Medical Sciences, USM, for his helpful advice in statistical analyses. Ms. Sui Mei Kee and Ms. Nuraza Othman, et al., of the Department of Neurosciences, School of Medical Sciences, USM, helped the experiment technologically. Professor Dr. Sharharum Shamsuddin and his lab in PPSK, Universiti Sains Malaysia helped us with cDNA clone and cRNA synthesis. The work was funded by the incentive grant (from Universiti Sains Malaysia), short term grant (304/PPSP/61312047, from Universiti Sains Malaysia), and FRGS grant (203/PPSP/6171155, from the Department of Higher Education, Malaysia) to Dr. Jingli Zhang and Professor Dato' Dr. Jafri Malin Abdullah et al.

\section{Authors' Contributions}

Conception and design: JZ, HM, AZMY, HO, ZI, JMA Analysis and interpretation of the data: JZ, HM, JHW, MB, AHI, AJL, HO, KTW

Drafting of the article: JZ, HM, JHW

Critical revision of the article for important intellectual content: JZ, HM

Final approval of the article: JZ, HM

Provision of study materials or patients: HM

Obtaining of funding: $\mathrm{JZ}$

Administrative, technical, or logistic support: AZMY, HO, ZI, JMA

Collection and assembly of data: JHW, MB, AHI, AJL, KTW

\section{Correspondence}

Dr Jingli Zhang MD, PhD (Military Postgraduate Medical School, Beijing, PR China)

Department of Neurosciences,

School of Medical Sciences,

Universiti Sains Malaysia,

16150 Kubang Kerian,

Kelantan, Malaysia

Tel: +609 7676300;

Fax: +609 7673833;

E-mail: drjlzhang@gmail.com

\section{References}

1. Whiting PJ. GABA-A receptors: a viable target for novel anxiolytics? Curr Opin Pharmacol. 2006;6(1):24-29. https://doi.org/10.1016/j. coph.2005.08.005 
2. Campo-Soria C, Chang Y, Weiss DS. Mechanism of action of benzodiazepines on GABAA receptors. Br J Pharmacol. 2006;148(7):984-990. https:// doi.org/10.1038/sj.bjp.0706796

3. Sieghart W and Sperk G. Subunit composition, distribution and function of GABA-A receptor subtypes. Curr Top Med Chem. 2002;2(8):795816. https://doi.org/10.2174/1568026023393507

4. Abdullah JM. Interesting asian plants: their compounds and effects on electrophysiology and behaviour. Malays J Med Sci. 2011;18(4):1-4

5. Malin Abdullah $\mathrm{J}$ and Zhang J. The GABA A receptor subunits heterologously expressed in Xenopus oocytes. Mini reviews in medicinal chemistry. 2013;13(5):744-748. https://doi. org/10.2174/1389557511313050011

6. Zhu HL, Wan JB, Wang YT, Li BC, Xiang $\mathrm{C}$, He J, et al. Medicinal compounds with antiepileptic/anticonvulsant activities. Epilepsia. 2014;55(1):3-16. https://doi.org/10.1111/epi. 12463

7. Treiman DM. GABAergic mechanisms in epilepsy. Epilepsia. 2001;42(Supp 3):8-12. https://doi. org/10.1046/j.1528-1157.2001.042suppl.3008.x

8. Zhang J, Mohamed Yusoff AA. A simple protocol of electrophysiological assays of $\alpha_{1} \beta_{2} \gamma_{2}$ S GABA A receptor in Xenopus oocytes. Feb. 2015. National library of Malaysia, Kuala Lumpur, Malaysia, ISBN 978-967-0486-56-7

9. Singhuber J, Baburin I, Ecker GF, Kopp B, Herring S. Insights into structure-activity relationship of GABA A receptor modulating coumarins and furanocoumarins. Eur $J$ Pharmacol. 2011;668(1):57-64. https://doi.org/ 10.1016/j.ejphar.2011.06.034
10. Schramm A, Ebrahimi SN, Raith M, Zaugg J, Rueda DC, Herring S, et al. Phytochemical profiling of Curcuma kwangsiensis rhizome extract, and identification of labdane diterpenoids as positive GABA A receptor modulators. $J$ Phytochem. 2013;96:318-329. https://doi.org/ 10.1016/j.phytochem.2013.08.004

11. Ha JH, Lee DU, Lee JT, Kim JS, Yong CS, Kim JA, et al. 4-Hydroxybenzaldehyde from Gastrodia elata $\mathrm{B} 1$. is active in the antioxidation and GABAergic neuromodulation of the rat brain. $J$ Ethnopharm. 2000;73(1):329-333. https:// doi.org/10.1016/So378-8741(0o)oo313-5

12. Matias M, Silvestre S, Falcao A, Alves G. Gastrodia elata and epilepsy: Rationale and therapeutic potential. $J$ Phytomed. 2016;23(12):1511-1526. https://doi.org/10.1016/ j.phymed.2016.09.001

13. Tao YH, Yuan $\mathrm{Z}$, Tang $\mathrm{XQ}, \mathrm{Xu}$ HB,Yang $\mathrm{XL}$. Inhibition of GABA shunt enzymes' activity by 4-hydroxybenzaldehyde derivatives. Bioorg Med Chem Lett. 2006;16(3):592-595. https://doi. org/10.1016/j.bcml.2005.10.040

14. Tao YH, Jiang DY, Xu HB,Yang XL. Inhibitory effect of Erigeron breviscapus extract and its flavonoid components on GABA shunt enzymes. J Phytomed. 2008;15(1):92-97. https://doi.org/ 10.1016/j.phymed.2007.06.009

15. Choi JJ, Kim YS, Kwon YO, Yoo JH, Chong MS, Lee MK, et al. 4-hydroxybenzaldehyde, one of constituents from Gastrodiae rhizoma augments pentobarbital-induced sleeping behaviors and non-rapid eye movement (NREM) sleep in rodents. Natural Product Sciences. 2015;21(3):219-225. 